\title{
RESEARCH OF WETTABILITY OF IN SOLDER ON AL2O3 Ceramic During Laser Beam Heating
}

\author{
Igor Kostolný, Roman Koleňák, Jozef Bárta \\ Slovak University of Technology in Bratilsava, Faculty of Materials Science and Technology in Trnava, Institute of \\ Production Technologies Paulínska 16, 91724 Trnava, Slovak Republic
}

\begin{abstract}
The work deals with investigation of wettability of In solder on $\mathrm{Al}_{2} \mathrm{O}_{3}$ ceramic substrate heated by laser beam. The soldering process was realized withou using od flux. Designed laser beam power was $1.1 \mathrm{~kW}$ and $0.5 \mathrm{~kW}$. The In solder of high purity of $5 \mathrm{~N}$ was used for soldering. Wettability of solder on substrate, microstructure of joints and EDX analysis on interface were evaluated. Satisfying value of wettability was observed only with power of laser beam $1.1 \mathrm{~kW}$. Lower power due to the high surface tension not allowing connection with a satisfactory value of wettability. Observation of microstructure confirmed the creation of reaction zone on joint boundary. EDX analysis identified the phase boundary witch is composed of mixture of $\mathrm{Al}+\mathrm{In}$ and $\mathrm{InO}_{2}$.
\end{abstract}

Keywords: solder; wetability; microstructure; EDX analysis, laser beam
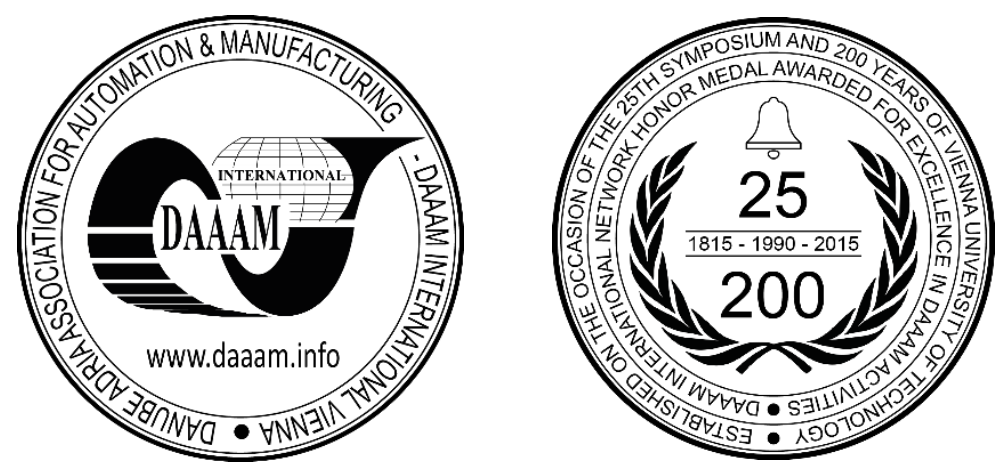

This Publication has to be referred as: Kostolny, I[gor]; Kolenak, R[oman] \& Barta, J[ozef] (2016). Research of Wettability of In Solder on A12O3 Ceramic During Laser Beam Heating, Proceedings of the 26th DAAAM International Symposium, pp.0704-0708, B. Katalinic (Ed.), Published by DAAAM International, ISBN 978-3-902734-07-5, ISSN 1726-9679, Vienna, Austria

DOI: 10.2507/26th.daaam.proceedings.097 


\section{Introduction}

Ductile soft active solders can joining unusual combinations of metallic materials (eg. stainless steel, Mo, W) and mostly non-metallic brittle materials (fused silica, sapphire, carbon, silicon). The basic material of soft active solders can be tin, lead or indium and created alloys based on these metals. Such joints are applied in electronics and electrical engineering, where it is sufficient to lower strength and thermal resistance of the joint. For example the connection of the heat exchangers to the ceramic electronic substrate of Al2O3 [1]. At present, however, they prefer soft lead-free solder mainly due to environmental friendliness and standards. Soldering of ceramic materials research deals with a number of universities and researchers in the world. The authors $[2,3,4,5,6]$ studied soldering of copper and Al2O3. Soldering by ultrasound ensure proper wetting and interaction between $\mathrm{Sn}$ solder and ceramic substrates.

The use of CuAgTi solder was successful in joining copper and Al2O3 ceramic. To improve wettability of solder Sn3.5Ag4Ti, a small amount of $\mathrm{Ce}$ and $\mathrm{Ga}$ was added. Best achieved wetting angle was $46^{\circ}$.The authors of $[7,8,9,10]$ used solder alloys based of $\mathrm{Cu}$ and $\mathrm{Sn}$ with the addition of Ti to improve wettability of solders on $\mathrm{Al} 2 \mathrm{O} 3$ ceramic substrate. This was due to lowering of interfacial tension by absorbing to liquid side of the joint. Likewise, reduction of tension by forming an oxide layer $\mathrm{TiO} 2$ at solid side of the interface.

The addition of In to the basic Zn solder and analyze its properties are dealt by authors [11, 12]. A small amount of In to $\mathrm{Zn}-\mathrm{Al}$ solder decreases the melting temperature. It also resulted in an increase of electrical resistance compared to $\mathrm{Zn}-\mathrm{Al}$ eutectic solder. The contact angle of the $\mathrm{Al}$ and $\mathrm{Cu}$ substrate is reduced with increasing of In content. $\mathrm{A}$ comprehensive overview of wettability of different solder alloys on ceramic material A12O3 is current problem of various research papers in the world. This work therefore deals with research of wetting of In solder on Al2O3ceramic material.

\section{Experimental}

The ceramic material aluminum oxide (A12O3) was used as a base material in experiments. Al2O3 substrate itself has been cut by water jet to size $\varnothing 15 \mathrm{~mm}$ (FIG. 1). Solder used for research of wettability was In having a purity of $5 \mathrm{~N}$.

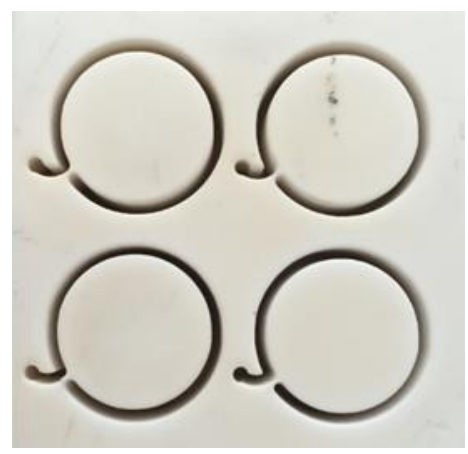

Fig. 1. $\mathrm{Al}_{2} \mathrm{O}_{3}$ substrate

Design of solder / substrate joint was carried out on solid-state disk laser with a maximum power of $2 \mathrm{~kW}$ from the Trumpf company. Before soldering, the samples were thoroughly cleaned. For each sample, defocussed beam of focus position $15 \mathrm{~mm}$ above the material was prepared. Designed laser beam power was $1.1 \mathrm{~kW}$, and $0.5 \mathrm{~kW}$. Schematic of laser beam soldering is illustrated in FIG. 2.

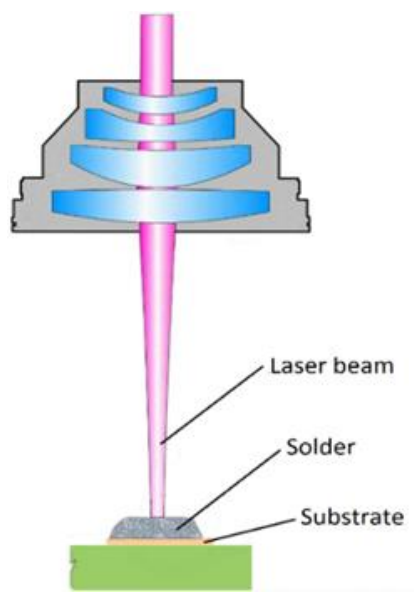

Fig. 2. Scheme of laser beam soldering 
After completion of joints, samples have been cut for the analysis of solder wetting angle. Analysis of the microstructure of joints were taken using scanning electron microscopy (SEM). The joint interface was evaluated by EDX analysis. Analyses were carried out on the equipment JEOL JSM - 7600F.

\section{Experimental results}

Wetting angle measurement was carried out on two samples (fig. 3). Soldering with laser power of $1.1 \mathrm{~kW}$ (fig. 3 a) reached the contact angle of $81^{\circ}$. The value of the surface energy is high, but in this case, a contact angle made best value. By reducing the power of laser beam to $0.5 \mathrm{~kW}$, the contact angle of $123^{\circ}$ was measured. Whereas the maximum satisfactory contact angle must be less than $90^{\circ}$, this angle was evaluated as unsatisfactory.

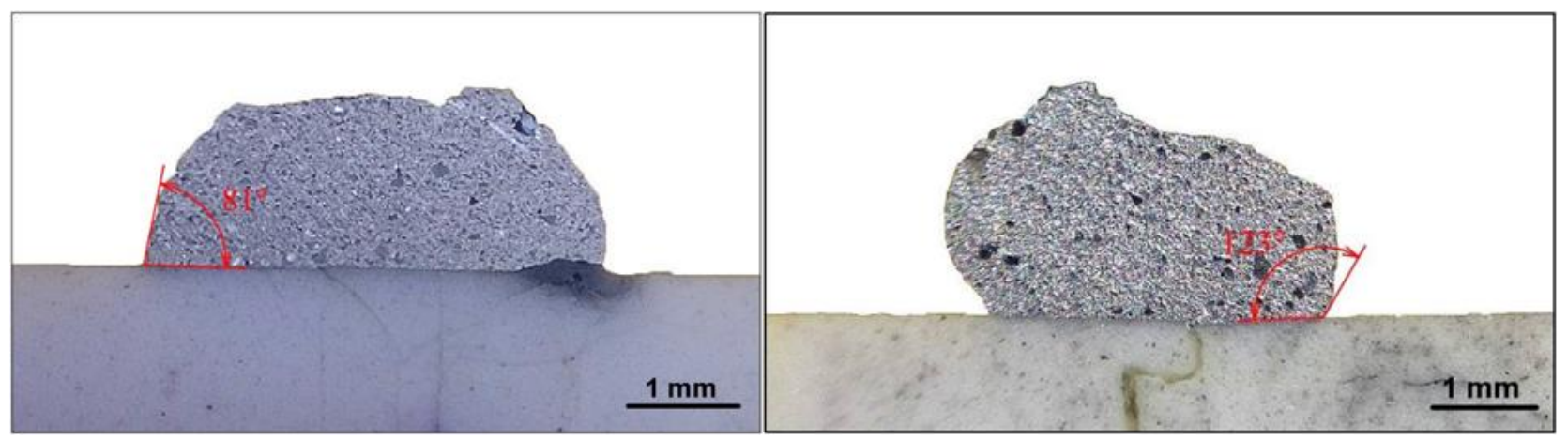

Fig. 3. Wetting behavior of $\mathrm{In} / \mathrm{Al}_{2} \mathrm{O}_{3}$ a) $1,1 \mathrm{~kW}$; b) $0,5 \mathrm{~kW}$

The microstructure of In solder / $\mathrm{Al}_{2} \mathrm{O}_{3}$ substrate joints is shown in fig. 4. The interface of joint is clearly visible. Dark particles in solder are the remains of $\mathrm{SiC}$ grinding wheel, which incurred during metallographic preparation of samples. Based on microstructure of the joint, interaction between the solder and substrate is obvious.

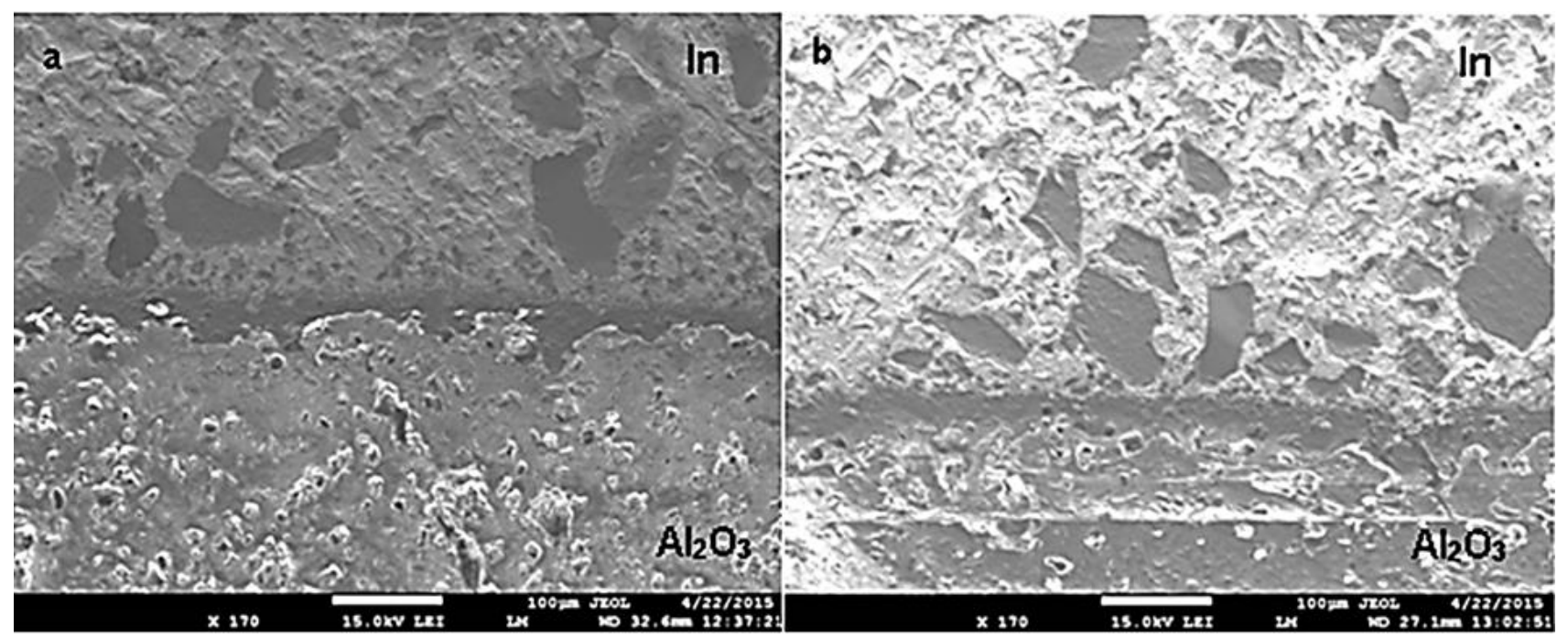

Fig. 4. Microstructure of joints interface $\mathrm{In} / \mathrm{Al}_{2} \mathrm{O}_{3}$ a) $1.1 \mathrm{~kW}$; b) $0.5 \mathrm{~kW}$.

EDX analysis was performed to determine the chemical composition of the interface of solder / substrate and to determination of the reactions that arose during soldering. The mixture of $\mathrm{Al}+\mathrm{In}$ and $\mathrm{InO}_{2}$ oxide were observed on interface in both cases. The measured reaction layer with thickness of 10 microns was observed after soldering with laser power of $1.1 \mathrm{~kW}$. Conversely, the use of $0.5 \mathrm{~kW}$, the thickness was lower by a half. The very formation $\mathrm{InO}_{2}$ reduces the surface tension between the solder and the substrate and thus enables better wetting of the substrate. 

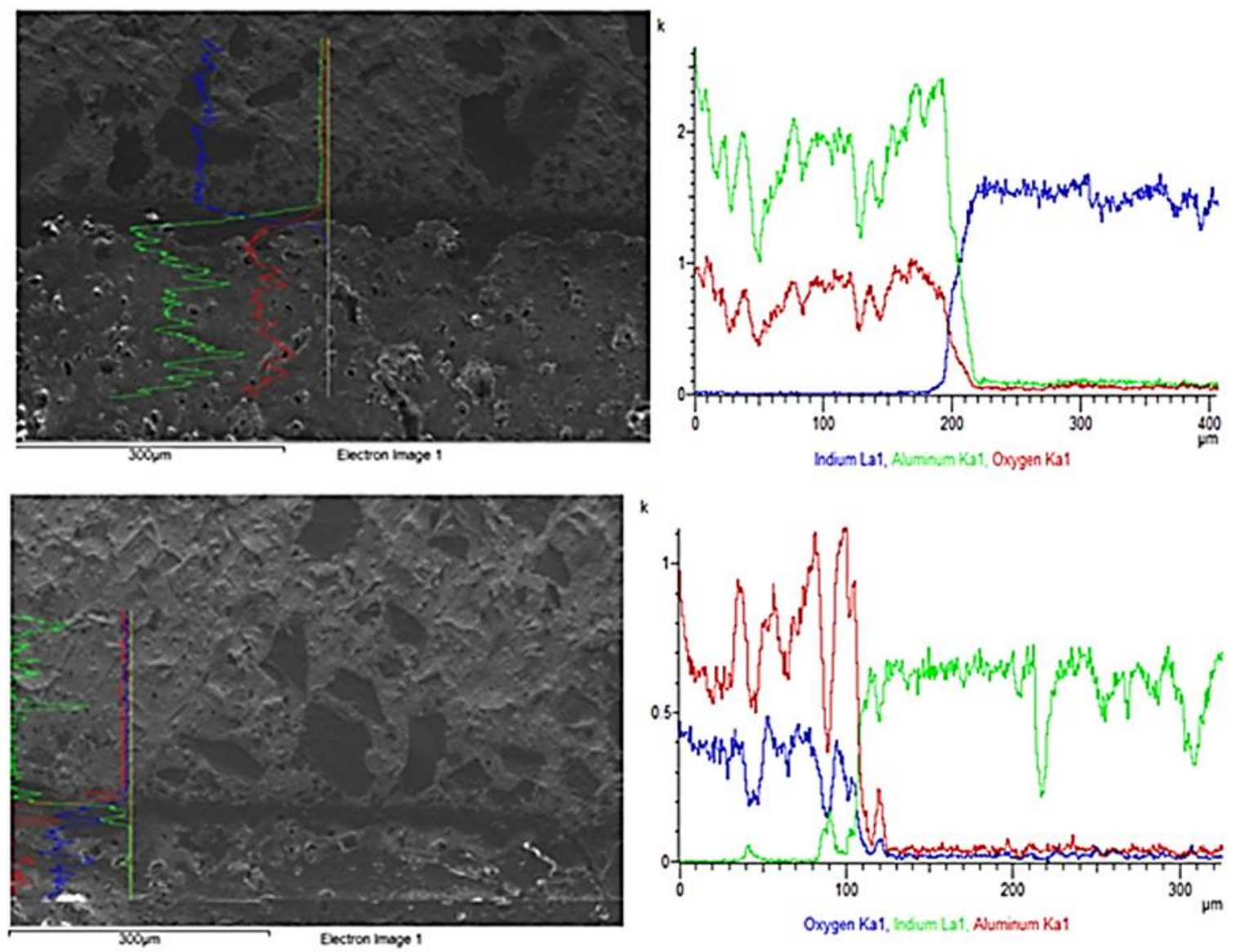

Fig. 5. EDX analysis of $\mathrm{In} / \mathrm{Al}_{2} \mathrm{O}_{3}$ a) $1,1 \mathrm{~kW}$; b) $0,5 \mathrm{~kW}$

\section{Conclusions}

The work deals with the research of wettability of In solder on $\mathrm{Al}_{2} \mathrm{O}_{3}$ ceramic substrate during laser beam heating. Designed laser beam power was $1.1 \mathrm{~kW}$ and $0.5 \mathrm{~kW}$. Soldering was carried out in the absence of flux. Prepared In solder was produced in high purity of $5 \mathrm{~N}$. The work evaluated the resulting contact angle, microstructure of the joints by scanning electron microscopy and EDX analysis to determine the phase composition of boundary. The results obtained can by summarized as follows:

- wettability of In on $\mathrm{Al}_{2} \mathrm{O}_{3}$ ceramic substrate was satisfactory with power of laser beam $1.1 \mathrm{~kW}$. Achieved wetting angle was $81^{\circ}$. With the reduction of power to $0.5 \mathrm{~kW}$, wetting angle increase to $123^{\circ}$,

- microstructure of the joints confirmed the formation of reaction layer between solder and substrate,

- EDX analysis revealed the presence of a $\mathrm{Al}+\mathrm{In}$ mechanical mixture and formation of $\mathrm{InO}_{2}$ surface oxide layer,

- $\quad$ better wetting angle was achieved due to reduction of surface tension by formation of $\mathrm{InO}_{2}$.

It was found that the In solder wets $\mathrm{Al} 2 \mathrm{O} 3$ ceramic substrate and creates a stable phases at the interface by correct parameter setting of laser beam soldering. Further research should deal with the study of the joint strength of this ceramic material using In as the solder.

\section{Acknowledgement}

The contribution was prepared with the support of APVV-0023-12: Research of new soldering alloys for fluxless soldering with application of beam technologies and ultrasound and VEGA 1/0455/14: Research of modified solders for fluxless soldering of metallic and ceramic materials.

\section{References}

[1] ŽÚBOR, P. KOLEŇÁK, R. 2013. Study of reaction interface of soldered combined materials. Zváranie -Svařování, 62 (7 - 8), ISSN 0044-5525.

[2] R. Koleňák, P. Šebo, M. Provazník, M. Koleňáková, K. Ulrich, Shear strength and wettability of active Sn3.5Ag4Ti(Ce, Ga) solder on Al2O3 ceramics, Mater. Des. 32 (2011) 3997-4003. 
[3] O. Kozlova, M. Braccini, R. Voytovych, N. Eustathopoulos, P. Martinetti, M.F. Devismes, Brazing copper to alumina using reactive CuAgTi alloys, Acta Mater. 58 (2010) 1252-1260.

[4] C. Beraud, M. Courbiere, C. Esnouf, D. Juve, D. Treheux, Study of copper-alumina bonding, J. Mater. Sci. 24 (1989) 4545-4554.

[5] H. He, R. Fu, D. Wang, X. Song, M. Jing, A new method for preparation of direct bonding copper substrate on A12O3, Mater. Lett. 61 (2007) 4131-4133.

[6] I. Foroutan, R.S. Mamoory, N. Hosseinabadi, Alumina-copper joining by the sintered metal powder process, Ceram. Int. 36 (2010) 741-747

[7] S. Chang, Y. Hung, T. Chuang, Joining alumina to Inconel 600 and UMCo-50 superalloys using an Sn10Ag4Ti active filler metal, J. Mater. Eng. Perform. 12 (2003) 123-127.

[8] R. Voytovych, F. Robaut, N. Eustathopoulos, The relation between wetting and interfacial chemistry in the CuAgTi/alumina system, Acta Mater. 54 (2006) 2205-2214.

[9] P. Kritsalis, L. Coudurier, N. Eustathopoulos, Contribution to the study of reactive wetting in the $\mathrm{CuTi} / \mathrm{Al} 2 \mathrm{O} 3$ system, J. Mater. Sci. 26 (1991) 3400-3408.

[10] S.Y. Chang, T.H. Chuang, C.L. Yang, Low temperature bonding of alumina/alumina and alumina/copper in air using Sn3.5Ag4Ti (Ce, Ga) filler, J. Electron. Mater. 36 (2007) 1193-1198.

[11] LEE, J., KIM, K., SUGANUMA, K., INOUE, M., IZUTA, G. Thermal Properties and Phase Stability of Zn-Sn and Zn-In Alloys as High Temperature Lead-Free Solder. In Materials Transactions, Vol. 48, 2007, 584-593.

[12] GANCARZ, T., PSTRUS, J., FIMA, P., MOSINSKA, S. Thermal Properties and Wetting Behavior of High Temperature Zn-Al-In Solders. In JMEPEG, Vol. 21 pp. 599-605. 